University of Nebraska - Lincoln

DigitalCommons@University of Nebraska - Lincoln

Sociology Department, Faculty Publications

Sociology, Department of

$12-2012$

\title{
Midwest or Lesbian? Gender, Rurality, and Sexuality
}

Emily Kazyak

University of Nebraska-Lincoln, ekazyak2@unl.edu

Follow this and additional works at: https://digitalcommons.unl.edu/sociologyfacpub

Part of the Gender and Sexuality Commons, Place and Environment Commons, and the Regional Sociology Commons

Kazyak, Emily, "Midwest or Lesbian? Gender, Rurality, and Sexuality" (2012). Sociology Department, Faculty Publications. 205.

https://digitalcommons.unl.edu/sociologyfacpub/205

This Article is brought to you for free and open access by the Sociology, Department of at DigitalCommons@University of Nebraska - Lincoln. It has been accepted for inclusion in Sociology Department, Faculty Publications by an authorized administrator of DigitalCommons@University of Nebraska - Lincoln. 
Published in Gender \& Society 26:6 (December 2012), pp. 825-848; doi:

$10.1177 / 0891243212458361$

Copyright ( 2012 by Emily Kazyak. Published by SAGE Publications on behalf of Sociologists for Women in Society. Used by permission.

A subscription version of this article is found online at http://gas.sagepub.com/content/26/6/825

The author would like to thank the people interviewed for this project for their time and willingness to share their stories. I am grateful for Julia Slagle, who provided excellent research assistance. I also owe many thanks to Laura Hirshfield, Nadine Hubbs, David Hutson, Julia McQuillan,Karin Martin, Helen Moore, Zakiya Luna, Carla Pfeffer, and Kristin Scherrer as well as the Gender \& Society Editor Joya Misra, Deputy Editor Mary Bernstein, and the anonymous reviewers for their helpful feedback on earlier drafts of this article. This research received no specific grant from any funding agency in the public, commercial, or not-for-profit sectors.

\title{
Midwest or Lesbian? Gender, Rurality, and Sexuality
}

\author{
Emily Kazyak \\ University of Nebraska-Lincoln, Lincoln, NE, USA
}

\begin{abstract}
Research suggests a gendered dimension to the geography of sexual minorities, as gay couples are more likely to live in cities than are lesbian couples. Using data from 60 interviews with rural gays and lesbians, this article employs an intersectional analysis of the mutually constitutive relationships among place, gender, and sexuality in order to assess how acceptance of gays and lesbians in small towns is gendered. Findings indicate that femininity aligns with gay sexuality but not rurality. In contrast, masculinity underpins both the categories "rural" and "lesbian." Furthermore, both lesbian women and gay men gain acceptance in rural areas by doing masculinity. This analysis indicates that masculinity is not something to which only male bodies are privy. In contrast to prior work, it shows one form of female masculinity that is normative rather than transgressive. The analysis also reveals that the meanings of gender presentations vary by geographical context.
\end{abstract}

Keywords: sexuality, men/masculinity, race, class, gender

Growing up in a small town, I worked on a farm. A lot of women worked on farms or in road construction or nontraditional jobs for women. I told somebody that if you were to drive by [my town], you'd think the place is full of lesbians! They're all wearing flannel shirts and cowboy boots.

This quote from one of my participants, Nancy, a lesbian woman living in a small Midwestern town, illustrates the way space, gender, and 
sexuality are intertwined and underscores two important issues. It indicates that gender presentations are central to understandings of sexuality, insofar as lesbian sexuality is conflated with masculinity. Masculine gender practices, from wearing flannel shirts to working in traditionally maledominated jobs, are part of how the category "lesbian" is constructed. Nancy's quote also indicates that such practices of masculinity for women in rural communities are "not uncommon," illustrating that the meanings of gender presentations vary by geographic context. Although female masculinity is the most visible gender presentation of lesbian identity in urban contexts, it does not have the same meaning in rural contexts, since both straight and lesbian women might enact it. People therefore might erroneously think her town is "full of lesbians" since all women might enact more masculine gender presentations.

Research does indicate a gendered dimension to the geography of sexual minorities. Gay couples are more likely to live in urban areas than are lesbian couples (Gates and Ost 2004, 28), suggesting that gender might matter for how sexual minorities experience rural areas. Drawing on data from 60 interviews with rural gays and lesbians, I analyze the mutually constitutive relationships among place, gender, and sexuality to assess how acceptance of gays and lesbians in small towns is gendered. I find that constructions of male femininity align with gay sexuality but not rurality, which may mean that for some gay men, the ability to stay put in rural areas might be constrained. However, masculinity underpins both the categories rural and lesbian, which may afford some lesbians the ability to stay in rural places. How these categories are co-constructed sheds light on the gendered nature of acceptance for sexual minorities in rural areas: Both lesbian women and gay men gain acceptance by doing masculinity.

My research extends existing knowledge about rural sexual minorities. Previous work focuses on gender as it matters for gay men (Boulden 2001; Gray 2009; Howard 1999). I show how gender matters for rural lesbian women. Likewise, being known as a good person and being able to assert belonging are routes to acceptance for rural sexual minorities (Gray 2009; Kazyak 2011a; Stein 2001). I highlight how these processes are gendered. Furthermore, focusing on how rural lesbians do masculinity, the current study provides an instance of female masculinity (Halberstam 1998). As such, it underscores the importance of recognizing that masculinity extends beyond male bodies (Pascoe 2007). Some research argues that women doing masculinity is culturally disruptive and personally transgressive (Halberstam 1998; Schippers 2007; Shapiro 2007). In contrast, my research shows that some practices of female masculinity are normative. 
Finally, it shows that the meanings of gender presentations differ not only by generation and race (Moore 2006) but also by geography. Female masculinity is the most visible gender presentation of lesbian identity in urban contexts (Kennedy and Davis 1993; Moore 2006, 117). However, it does not hold the same meaning in rural contexts, because masculine gender presentations are acceptable for all rural women, regardless of sexuality. Before turning to these findings, I outline the theoretical and empirical literatures that frame this study, and detail its data and methods.

\section{Literat ure Review}

\section{Intersectionality and Masculinity}

Intersectional approaches consider how the categories and identities of race, class, gender, and sexuality (Bettie 2003; Hill Collins 1990; Nagel 2003; Wilkins 2004) are constructed simultaneously. For example, in her work on the gendered-classed-raced category "Puerto Rican wannabe," Wilkins (2004) demonstrates how sexuality works in constructing this category, insofar as it refers to white young women who, among other things, date Black and Puerto Rican men and thus eschew white middleclass gender and sexual norms. The current study employs a similar type of analysis in its focus on how the construction of sexual and spatial categories rests on meanings shaped by gender. Although the primary focus is on gender, race similarly impacts the dynamics of acceptance in small towns. Specifically, asserting sameness is crucial to being seen as belonging in rural communities. The racial homogeneity in rural areas (U.S. Bureau of the Census 2000) no doubt means that whites, unlike people of color, have a greater ability to assert such belonging and have it legitimated.

Additionally, I draw on theories of masculinity. Scholars define masculinity as encompassing both practices (what people do-gender displays) and discourses (assumptions and expectations about what men and women should be like) (Connell 1995; Pascoe 2007; Schippers 2007). Importantly, the practices and discourses that establish what it means to be an ideal man position femininity and other kinds of masculinities as subordinate and thus justify and perpetuate gender inequality and male dominance (Connell 1995). Recently, scholars have asserted the need to extend beyond a definition that ties masculinity to what men do, arguing that women (and girls) also engage with masculinized practices and discourses (Halberstam 1998; Pascoe 2007). Building on such work, this article extends analyses of gender by focusing on a neglected group within 
masculinity studies: women. It provides more empirical evidence of the importance of not reducing masculinity to the male body and femininity to the female body.

Halberstam (1998) calls women's engagements with practices and discourses associated with masculinity, including embodying and performing masculinity, "female masculinity." Such engagements can shape people's own transgressive sense of gender identity. Shapiro (2007), for instance, finds that through participating in drag king troupes, many participants adopt new gender identities, including "genderqueer" and "butch," and see themselves as "gender outlaws." Moreover, female masculinity is culturally disruptive (Halberstam 1998). Since U.S. culture so tightly links masculinity with maleness, Halberstam (1998) notes the paradox that masculinity enacted by women has been both ignored and met with much anxiety. For instance, butch lesbians, one exemplar of women's embodiments of masculinity, have been pathologized (Halberstam $1998,9)$. In fact, some argue that when women enact features of dominant masculinity, it should not be considered masculinity, but rather "pariah femininity," given that it is seen as contaminating the appropriate relationship between masculinity and femininity (Schippers 2007). Schippers (2007) also argues that such enactments are met with stigma and disapproval.

Yet other work shows that some forms of female masculinity are accepted (Pascoe 2007). In other words, when girls or women enact masculinity, it is not always met with hostility. In her ethnography, Pascoe (2007) highlights two groups of high school girls who were considered masculine by themselves and others. The masculine practices of one group - the "basketball girls" - including dressing like boys and being aggressive, were accepted by their peers. And not only were they accepted but those practices increased the girls' popularity and social status (Pascoe 2007, 120). Likewise, Pascoe (2007) argues that not all enactments of female masculinity challenge the gender order. Only those enactments that are coupled with an explicit, critical assessment of the accepted gender and sexual norms are challenging.

Scholars have also addressed contexts in which women (and men) can produce alternative genders and redefine the relationship between masculinity and femininity - what Schippers (2002) calls "gender maneuvering." In alternative hard rock subcultures, for example, girl bands challenge the homophobia common in rock as well as transform stigmatized femininities (like "slut" or "bitch") into markers of power. In her ethnography of the sport of roller derby, Finley (2010) also finds that women in this context are able to cultivate alternative femininities. Similarly, drag 
performances can challenge dominant understandings of gender and sexuality (Rupp, Taylor, and Shapiro 2010). However, not all forms of gender resistance result in a disruption of the gender order. Synthesizing across previous work, Finley asserts that in contexts where men dominate and control resources, it is less likely that women's enactment of unconventional femininity will transform the gender order $(2010,366)$.

In sum, scholars point not only to women's gender identity (exemplified by women who are seen by themselves and others as more masculine) but also to women's engagement with practices and discourses associated with masculinity to provide examples of female masculinity. In this article, I too draw on participants' gender identity and their engagement with practices and discourses associated with masculinity in rural areas, including doing farmwork or being "country" or "redneck." Debate exists regarding whether female masculinity, and other enactments of alternative genders, challenges or reproduces the dominant gender order. Similar to Pascoe's work, this article provides an example of a context wherein female masculinity is not necessarily stigmatized, presenting an account of which women's engagements with practices and discourses associated with masculinity are seen as normative and which are seen as disruptive. As such, this work illustrates the importance of addressing how context matters for how female masculinity is viewed.

\section{Rural Gender and Sexuality}

Research reveals the patriarchal nature of rural life, but simultaneously recognizes the multiple masculinities that exist in rural communities and that rural masculinities change (Campbell, Bell, and Finney 2006). Working and laboring are crucial to constructions of masculinity. In contrast, constructions of rural femininity are tied to domesticity (Hughes 1997; Little and Austin 1996). These constructions of masculinity and femininity work to sustain gender inequality insofar as they justify men as rightfully positioned in paid labor, public spheres and women in unpaid, private spheres. For instance, Bird (2006) illustrates how male owners of rural small businesses are seen as providing for their families and for the community itself by employing men who in turn take care of their families. When women work in these small businesses, they are viewed as helpers. The same is true in farming, where farmwork is seen as the sole domain of men and women are seen as helpers in the domestic sphere (Sachs 1983). Even with the increasing absence of traditionally defined male jobs in rural areas due to economic restructuring (Falk and Lobao 2003), physical toughness continues to constitute local construc- 
tions of masculinity (Morris 2008). Hard work and laboring are also part of what it means to be a "local," which contributes to the alienation and possibly even departure of groups positioned outside of working and laboring, including women (Campbell, Bell, and Finney 2006; Laore and Fielding 2006).

This is not to suggest that no women stay in rural areas or work in small towns. Indeed, many women want to stay, even if opportunities exist elsewhere (Tickamyer et al. 2000). Also, Tickamyer and Henderson (2003) find that rural economic restructuring has necessitated the presence of women in the paid labor market. Nonetheless, research suggests that domesticity remains central to constructions of rural femininity. Taking care of the home and family are important routes to achieve femininity and are often seen as incompatible with paid employment (Little 1997). Rural women's caretaking expectations even inform rural activism (Bell and Braun 2010). The emphasis on domesticity underscores how heterosexuality underpins rural femininity. Some suggest that heterosexuality and domesticity are so central to constructions of rural femininity, in part, to combat the fact that some practices commonly performed by rural women, such as being outdoorsy or doing farmwork, are masculinizing (Smyth 2007). In this way, whereas "rural men equal real men" (Sachs 2006, 2), the opposite is true for rural women. Indeed, some rural women struggle with being perceived as masculine and work to assert femininity (Brandth 2006; Smyth 2007). Yet others view rural areas as offering the space to reject traditional notions of femininity, namely, women part of lesbian land movements (Bell and Valentine 1995).

Constructions of rural masculinity and femininity matter for the experiences of rural gay men, as those who are perceived as feminine face greater hostility than those who are perceived as masculine (Boulden 2001; Gray 2009; Howard 1999). Analyzing a bashing that occurred after a drag performance at a local Wal-Mart, Gray (2009) links the bashing to the fact that the young men were transgressing gender norms. She argues that for rural men, "publicly disrupting normative gender expectations arguably remains as, if not more, contentious than homoerotic desires" (Gray 2009, 110). Yet other research suggests that some gender nonnormative Black men in small towns in the South find acceptance (Johnson 2008), indicating a complex interplay among identities of rurality, region, masculinity, race, and sexuality. Furthermore, there have been movements, such as the radical faeries, to create rural spaces where men can reject traditional notions of masculinity (Hennen 2008; Herring 2007). These accounts provide rich detail of how gender expectations matter for 
gay men in rural places, but we know less about the experiences of lesbian women. This article fills this gap.

Informed by these theoretical and empirical literatures, this study asks how acceptance for rural sexual minorities is gendered. Utilizing a definition of masculinity that encompasses identity, practices, and discourse reflects the fact that some rural gay men and lesbian women described their own gender identities or gender displays (practices), while others talked more explicitly about the expectations that circulate in rural areas about what men and women are supposed to be or do (discourses). As in previous work, I find constructions of masculinity to entail laboring, working hard, and being tough. I also find heterosexuality and domesticity to be important parts of constructions of rural femininity. Unlike the radical faeries, the gay men in this study did not reject masculinity. The rural lesbian women were not part of lesbian land movements, although they did reject traditional femininity. Unlike rural women in previous studies, many defined their gender as more masculine, engaged with masculinized practices and discourses, and did not express discomfort about others perceiving them as masculine. Both rural gay men and lesbian women engage with practices and discourses associated with masculinity, which bolsters their acceptance in small towns. Importantly, not all female masculinities are wholly accepted in rural areas, including practices and discourses that are seen as antithetical to what it means to be "country."

\section{Methods}

\section{Data Collection and Analysis}

Data come from 60 interviews with Midwestern rural gays and lesbians. Half had grown up in rural locales and were living in urban areas at the time of the interview, and 30 were living in rural locales. Interviewees were recruited from Michigan and Illinois, a decision that was driven by the similarities of the states in regard to characteristics of both gay and lesbian life and rural life. I recruited participants through both LGBTspecific (e.g., LGBT publications and organizations) and general venues (e.g., Craigslist). I also recruited participants through snowball sampling. I conducted most of the interviews in person and 13 by telephone. Prior to the interview, I asked people to complete a short demographic survey, which included a question asking them to describe their gender. ${ }^{1}$ The interviews were semistructured and covered ques- 
tions about the areas where they were living and grew up, their experiences coming out, and their experiences as a lesbian woman or gay man in the area in which they were living. I often asked follow-up questions that were unique to individual interviews. In talking about their gay or lesbian identity, interviewees often used gendered distinctions; other times gender emerged as interviewees described their small towns. Some interviewees spoke explicitly about their own sense of gender identity, which entailed more detail than their identification as "man" or "woman" they noted on the demographic survey.

Once the data were collected, I transcribed the interviews and coded them using QSR-NVivo software. I began analyses by reading through the transcripts and taking notes on interesting emerging themes. Some of the topics relevant to this article that emerged in this process that Emerson, Fretz, and Shaw (1995) refer to as "open coding" include participants' discussion of the assumption that to be gay means to be effeminate and to be lesbian means to be masculine, and their noting the importance of being recognized as a good person and hard worker. After generating these topics, I trained a research assistant to code the interviews using these indicators. The research assistant also looked at those interviewees who had described their gender identity or presentation, and generated a list of the descriptions. After the data were coded, I wrote analytic memos that linked themes, which were developed into the results shown here.

\section{Profile of Participants}

I use the definition of rural that encompasses areas with populations less than 50,000 provided by the United States Department of Agriculture (USDA 2007), though most towns were much smaller. Other demographic characteristics of the sample are listed in Table 1, including age, race (predominately white), and gender (predominately women). The racial composition of the sample reflects the demographics of rural Michigan and Illinois (where 96 and 97 percent, respectively, of the population is white) (U.S. Bureau of the Census 2000). However, given that gay and lesbian identity is often construed as white (Almaguer 1993) and that bisexuals are more likely to be a racial minority than gays or lesbians (Gates 2010), the sample may have included more people of color if I had recruited people who had same-sex attraction (but did not necessarily identify as gay or lesbian) or people who identified as bisexual. The small number of gay men interviewed reflects a limitation of this sample. One reason for this disparity is my recruitment method: The majority of women (70 percent) were recruited through a national lesbian-spe- 
Table 1. Characteristics of Interviewees

\begin{tabular}{lcc}
\hline & $\begin{array}{c}\text { Residing in } \\
\text { Rural }(\mathrm{n}=30)\end{array}$ & $\begin{array}{c}\text { Residing in } \\
\text { Urban }(\mathrm{n}=30)\end{array}$ \\
\hline Age & $24-55$ & $21-68$ \\
Range & 41 & 41 \\
$\quad$ Average & & 24 \\
Gender & 19 & 6 \\
$\quad$ Women & 11 & 29 \\
$\quad$ Men & & \\
Race & 23 & \\
White & 1 & \\
Asian & 1 & \\
Hispanic & 1 & \\
Biracial & & \\
Area & 15 & \\
Less than 2,500 & 7 & \\
Less than 10,000 & 8 & \\
Less than 50,000 & & \\
\hline
\end{tabular}

cific publication based in Michigan (Lesbian Connection). I did not recruit through such an equivalent publication aimed specifically at gay men.

Among the women who described their gender in the interviews, only three women, Debbie, Terri, and Elise, who were all living in urban areas, saw themselves as more feminine, using descriptors like "femme" or "femmy." Evelyn said she sees herself as both butch and femme. The other women described seeing their gender as more on the masculine end of a spectrum. Some of the descriptors these women used included "tomboy," "soft butch," "butch," and "butchy." When explaining their gender, most interviewees pointed to dress, mannerisms, and hobbies. For instance, Joan said: "I'm kinda butchy because I can drive heavy equipment, I'm a handy person, I drive big trucks." Heterosexuality was also a part of how women talked about their gender. Alice, for instance, described herself as a "tomboy" and "old maid," both of which tied to a lack of heterosexuality. She said: "I had the tomboy look ... so I wasn't the type that guys would be asking out to the dances [because] they wanted the pretty girls, the cheerleaders." Similarly, she said, "I'm kinda old maid-looking, the kind of girl you might assume wasn't married." Her descriptions underscore the assumption that part of what constitutes rural femininity is heterosexuality.

Men also pointed to their dress, mannerisms, and hobbies to describe their gender. More men described their gender as masculine than feminine. Rich called himself an "average male." Jesse described himself as 
"not flamboyant," which resonated with Justin's assessment of not fitting the "effeminate gay male stereotype." Jake noted that his friends refer to him and his partner as their "flannel gays." There were, however, four men who described their gender as more on the feminine end of a spectrum, including Kevin, who said, "I'm a flamer," and Adam, who said, "I'm not the most masculine person in the world."

By offering this general sketch, I do not intend to erase the fact that people's understandings of their gender were complex. Some noted that how they think about their gender has changed throughout their lives. Some talked about the discrepancies between how they and their partners see their gender. This begs interesting questions about how geographic context might shape both the way sexual minorities make sense of their gender identity and the content of certain gender identity categories.

However, the goal of this article is not to assess why people described their gender in a particular way. Rather, I use the way people made sense of gender as one piece of evidence to illustrate that categories of space, sexuality, and gender intersect to create gendered acceptance of rural sexual minorities. To that end, I use "masculinity" and "butch" when talking about lesbian women's genders that interviewees understand as more masculine. Given the association between "butch" and "masculinity" at the level of culture and identity (Halberstam 1998; Levitt and Hiestand 2004; Rubin 1992), I understand participants' engagement with butchness to be an example of female masculinity. I use "femininity" and "effeminacy" when talking about gay men's genders that interviewees understand as more feminine. However, it is important to recognize that gender identity categories conceal practices that might be inconsistent with the associated identity (Valochhi 2005). People might claim a butch identity but still engage with practices and discourses associated with femininity or reject certain masculinized practices and discourses. Furthermore, it is important to note that one's gender expression tells us little about one's gender politics (Moore 2006). ${ }^{2}$

In order to ensure confidentiality, I have not used any names of towns or people in the findings I present here. The quotes have been edited for the sake of both confidentiality and clarity, but the meaning and words have not been otherwise changed.

\section{Coconstructions of Rurality, Gender, and Sexuality}

Using an intersectional approach highlights how understandings about gay and lesbian sexuality, masculinity and femininity, and urban and rural are constructed simultaneously. I first describe how both men 
and women thought that being gay or lesbian meant enacting nonnormative gender. I then describe how interviewees articulated an understanding that gay femininity is not compatible with rurality, whereas lesbian masculinity is. Whereas both gay and lesbian sexualities are intertwined with gender nonnormativity, the category "gay" shares a different relationship to rurality than does the category "lesbian."

\section{Gay Femininity and Lesbian Masculinity}

Interviewees repeatedly talked about the equation of gay male sexuality with effeminacy. Adam described the stereotypes he once had about gay men in this way: "Theater, drama, music, you have to dress nice ... you have to be kinda effeminate, you have to be very effusive and talk in a high voice." Justin's description echoes Adam's. When discussing the stereotype of a gay man, he said:

That feminine guy, that cross-dressing [guy], the guy that acts like a woman, that doesn't play sports, [is] into fashion and makeup and hair and shopping, and [who] does nothing that a typical straight guy would do [like] run outside with a chainsaw cutting a tree down, working in the yard, building stuff, and playing sports.

Jesse agreed, saying, "I guess I just thought that if you're gay, you have to act really flamboyant and queeny."

Women also described the model of same-sex sexuality that collapses lesbianism with masculinity. Elise said, "I would never have thought that you could be a lesbian and look feminine." Chelsea and Andrea, a lesbian couple who both participated in the project, described a magnet on their refrigerator that said: "I once was a tomboy but now I'm a lesbian." Similarly, Jenny referenced how she had the "stereotypical" markers for being lesbian growing up: "[I] played softball, I was a tomboy, [had] short hair, hated to dress up. I'd rather be outside doing something than bored and playing a musical instrument." Stephanie said, "I don't dress the most feminine and that usually leads people to stereotype me as a lesbian." Here participants both reference their own sense of gender and circulating discourses about what it means to be a lesbian.

\section{The Compatibility of Gay (Effeminate) and Lesbian (Butch) with Rurality}

The construction of gay as effeminate also contains geographical meanings, namely, as being incompatible with rurality. In contrast, lesbian as butch coincides with rurality. The incompatibility of rurality and 
effeminacy is evident in how interviewees described gender expectations for boys and men in small towns. Phil said, "I think in a rural area, if you're not into the sports, if you are interested in theater, then that causes a lot of problems, because [with] all these farm boys, you're supposed to be into the football and wrestling." Todd explained how his dad forced him to participate in sports: "You've got to, this is what little boys do in [this town]." Experiences Alice had going to gay bars in a nearby city when she first came out further underscores this point: "It was mostly made up of flamboyant, soft-spoken, and sensitive [gay men]. Growing up in [my town], I wasn't exposed to that." These quotes indicate the degree to which feminine characteristics conflated with gay sexuality, such as being flamboyant, soft-spoken, sensitive, or interested in theater, do not fit with the gender expectations for rural men.

That most of the men living in rural areas created a distinction between their sexuality and discourses about effeminate gay sexuality illustrates another way that rurality and effeminacy are constructed as incompatible. Except for Kevin, all men distanced themselves from the gay as effeminate model. Gene adamantly expressed this distancing: “I don't wanna be lumped together with a bunch of homos running around dressed in women's clothes, funky make-up, [and] dancing to Cher." Justin also made a distinction between his identity and what he sees as a stereotypical feminine gay identity, saying: "I'm not that guy." He elaborated:

I don't mind shopping, but I'm not into fashion. If you look at [how] I'm dressed today, I'm dressed like any normal person would be: I have a T-shirt and blue jeans on. I have three chainsaws at home. I love being outside. I love playing sports. I love to do home projects. I've got my power tools and I know how to use them.

Interestingly, Justin links his sense of not being what he sees as a stereotype to living in a small town:

Being here really changed my mindset because ... I was getting flirted with what I thought were straight men ... [but] they weren't straight men, they were gay men, but they looked very straight, they acted very masculine ... that changed everything. It was, like, this wasn't what I thought of as a gay man. So being in this town really changed how I thought of myself and the gay community. I was really happy that I could be a normal masculine type guy and be gay and not be ... the stereotype.

As Justin's words underscore, what it means to be a "normal, masculine" rural guy conflicts with femininity, including gay male effeminacy 
associated with urban spaces. Distancing their identities from femininity strengthens the ability of rural gay men to pursue local masculinity.

By contrast, rurality and more butch-like gender presentations are constructed as compatible. One way this compatibility is demonstrated is in how interviewees explained that rural areas allowed for, as Teresa put it, "a range of female gender." By this, interviewees meant that it is acceptable for women to do masculinity. ${ }^{3}$ Although some practices of masculinity are accepted, interviewees also articulated the expectation that women be heterosexually married and have children. As Natalie said, "It's just that mentality there that a woman can't live without a man, that you have to be married and you have to have 13 kids." Even though women can do things associated with masculinity, rural femininity still rests on heterosexuality and domesticity.

Explaining the "wider" range of female gender in rural areas, Teresa said, "There were farm girls [who] might dress up for the prom, but they also could slaughter a hog." Many had childhood stories relating to the fact that, as Lisa put it, "Tomboyishness was somewhat more acceptable than it might be somewhere else." Echoing this observation, Ester talked about her enjoyment of being raised on a farm: "I helped my dad a lot on the farm, raising ... livestock. ... I really enjoyed driving the farm machinery! It just empowered me, driving a tractor or truck." Ester's quote shows how some practices associated with masculinity are not seen as inappropriate for girls or women in rural contexts. In Rita's story, playing sports entailed being around a lesbian community while growing up in a small town. She said, "I played softball, so I was around really strong women and a really strong lesbian community from almost day one. I didn't get negative feedback from that." Her story, along with the others', underscores that gender expectations for rural women complement the discursive construction of lesbian sexuality that conflates it with masculinity.

Furthermore, most of the women living in rural areas did not create a distinction between their own gender and sexual identity and butch lesbian sexuality. There were nuances in how women talked about "butchness" ("butch," "soft butch," and "butchy"). However, there was not the same distancing from the gender nonnormative model of lesbian sexuality as there was for the gay men I interviewed. Take, for instance, Jenny, who described herself as butch, a stereotypical lesbian, and as a "redneck": "I'm so excited to go to the old gas tractor show. We fix our own things, we build our own stuff." When I asked if being a redneck fit with being a lesbian, she said, "Oh, it fits perfectly! It fits perfectly with being butch, but wouldn't fit at all [with] being femme." A similar narrative emerged in Tara's interview: "I ride a Harley. ... I have two dogs, 
[the] stereotype, you know, I play softball. Yeah, it all fits!" Here she references one stereotype of being a lesbian, including riding a motorcycle, having dogs, and playing softball. She said that her last girlfriend told her she looked "butchy" or "softbutch," adding, "I always have boots on. ... I'll never wear a dress ... and all the Harley stuff." The stereotype of being a lesbian equates with being "butchy," and in her case, driving a motorcycle exemplifies both.

Later in the interview, Tara also pointed to riding a Harley as one of the components that makes her think of herself as "country" or a "good old redneck girl." She explains: "I mow for farmers or do fieldwork. [I] haul grain ... I'm a redneck because I drive a Harley, [because] I drive a $4 \times 4$, [because of] the way I dress and I clod around." This example illustrates that it is not uncommon for rural women to engage in practices associated with masculinity, such as those she describes. Moreover, her comments illustrate that lesbian-butch and rural are seen as compatible. Some of the components that make her fit the stereotype of a lesbian are the same ones that make her "country."

For most of the gay men, living in a small town entailed not enacting gender presentations stereotypically associated with their sexual identity. The opposite was true for the lesbian women. They enact masculinity by claiming more butchlike identities and engaging with practices and discourses associated with masculinity in rural contexts. Their identification as "country" or "redneck" further signals the degree to which rural women can embrace traditionally masculinized redneck discourses (Hubbs 2011). Importantly, these lesbian-butch-rural identities are white insofar as the components of these identities are different, for instance, from what constitutes more masculine gender practices in urban Black lesbian communities (Moore 2006).

In highlighting these narratives, I do not intend to argue that only butch lesbians live in rural areas. Rather, the only lesbian women I was able to recruit from small towns saw their gender as more masculine. This might reflect the fact that even though rural women commonly engage in practices like farmwork or being outdoorsy, these practices are still associated with masculinity, which impacts rural women's gender identities (Smyth 2007). It could also be that those who do not adhere to rural masculinity leave for more urban areas, as Laore and Fielding (2006) suggest. Relatedly, participating in urban lesbian communities might entail exposure to a diversity of lesbian gender identities, including femme lesbian. These questions warrant attention in future research. Here, I argue that the way in which spatial, gender, and sexual categories are mutually constitutive has implications for the gendered nature of acceptance for rural sexual minorities, as I now turn to. 


\section{Gendered Experiences in Rural Areas}

Census data indicate that more lesbian women than gay men live outside urban areas (Gates and Ost 2004), which raises a question about the gendered experiences of sexual minorities in rural areas. I focus on acceptance and visibility in addressing this question.

\section{Acceptance}

Rural gays and lesbians describe that being seen as belonging in their communities bolsters others' acceptance of their sexuality (Gray 2009; Kazyak 2011a). What it means to belong is informed by class and racial meanings, insofar as being a "hick" is one way to signal an embrace of rural ways of life (Kazyak 2011b). The term hick creates a distinction between privileged (hick) and polluted (white trash) whiteness and illustrates how rural is constituted as white (Wray 2006). I argue that understandings about what it means to belong are not only classed and raced but also gendered. For gay men and lesbian women, being accepted as a good person who belongs entails embracing masculinizing practices and discourses.

Consider the two narratives presented earlier from Tara and Jenny. They both understood that being country, being a lesbian, and being more masculine entails similar interests and activities. That Tara is a "country girl" who has lived in the same area where her family has been for generations is part of her understanding about why she is accepted as an out lesbian woman in her town. Importantly, the country and "butchy" aspects of her gender are one and the same. However, not all female masculine gender presentations are seen as so intertwined with being country. Some presentations, as Rita's story illustrates, might be seen as urban and thus as incompatible with a rural way of life. Rita talked about how she has a "more urban look," noting that her "hair's cut off." When I asked her to elaborate on what she meant by an "urban look," she said, "My hair's bleached and sometimes I dye the tips. ... I tend to wear sweaters and neat ties and things that you wouldn't see a lot of in rural areas." She also told a story about visiting her hometown after cutting off her hair: "People were staring at me and I was, like, 'Why are people staring at me?' I couldn't for the life of me really wrap my mind around it until I realized, 'Oh my god, I look totally different than everybody else here.'" This quote suggests that female masculinity is read differently across geographic contexts. Rita links short hair, dyed tips, and wearing ties to urban settings and tells a story of being stared at in a small town 
because of such gender presentations. This is in contrast to what others said: that they did not necessarily feel out of place for looking more masculine. These narratives suggest that only practices of female masculinity that underpin what it means to be country are accepted.

Unlike female masculinity, no practices of male femininity cultivate claims to belonging. Many interviewees spoke of how effeminate men face disapproval and harassment in their towns. Consider, for instance, Tom, who spoke of his concern growing up about being "too femmy." He said, "I started smoking [because] I was afraid my voice wouldn't get deep enough and I didn't want anybody to think I had a lisp and that I was too femmy." Likewise, Kevin explained how his manager at work told him he needed to "learn how to drop my voice." Bethany reflected on how high school officials "were very harsh on boys," noting that "the guys who were thought to be a little more effeminate were pulled in once in a while and told by the superintendent how [they're] expected to behave." Xander, who lives in an urban area, talked about feeling uncomfortable when going back home: "I'm not the biggest flaming person, but I feel like I'm well enough on that way, that I feel like people [think] it's a little off." To further explain his point, he brought up the example of getting his car fixed: "When I go home and I'm going to get my oil changed ... and they're, like, 'What about this gauge?' and I'm, like, 'I have no idea what you're talking about!' I see the way that people look at me."

Indeed, doing masculinity strengthens claims to belonging and thus acceptance for gay men living in small towns. Jake was typical of those who were currently living in a small town: He saw his identity as distinct from effeminate gay sexuality. He said that his friend refers to him and his partner as her "flannel gays." Elaborating on that description, he said, "We're always doing projects outside in the yard, building things. So yeah, sometimes I guess I feel like a little bit of a hick ... maybe that's why I fit in so well up here!" In Jake's assessment, the fact that he is a "little bit of a hick" is tied to his engagement with practices of rural masculinity. Importantly, he also points to these facts as reasons why he "fit[s] in so well up here." Like practices of female masculinity, practices of male masculinity can signal belonging in small towns.

Xander also expressed a sense that masculinity could lead to acceptance in small towns: "I think it has to do with what you do [or] how you make your living. ... If you're a flaming gay queen, they're like, 'Oh, you're a freak, I'm scared of you.' But if you're a really butch woman and you're working at a factory, I think it's a little easier." He thinks acceptance is easier "if you're doing something that the town thinks is really useful to the community, [or if you're] doing the things that they're 
doing." Acceptance is predicated on masculinized discourses of work and "use" in the community-and a "flaming gay queen" is seen as having little ability to contribute to the community, in contrast to a "butch woman."

Like gay men who distanced themselves from effeminacy, lesbian women embraced practices and discourses associated with masculinity. In fact, female masculinity, so long as it was entangled with the country rather than the city, further strengthened women's ability to assert belonging in small towns. Since being able to signal belonging is integral to having one's sexual identity accepted, these data highlight how the nature of acceptance for rural gays and lesbians is gendered.

\section{Visibility}

Another way that the experience of sexual minorities in rural towns is gendered is that, unlike effeminacy, which is assumed to be linked to gay sexuality for men, more masculine gender presentations are not understood as linked only to lesbian sexuality for women. Therefore, visibility of lesbian identity is achieved differently in rural areas than in urban areas. Unlike in urban areas, more butch gender presentations are not enough make lesbian identity visible in rural areas. Rather, being seen around town with a same-sex partner is a way lesbian sexual identity is visible in rural areas given the close-knit nature of rural life. Thus, one route to visibility in rural contexts is relational (via connection with a same-sex partner) rather than individual (via butch gender presentations).

Speculating on how effeminate men are visible in rural areas, Xander said: "I think it'd be hard anywhere rural if you were, like, a really flamboyant gay guy. There's really no way to read that [other than] feminine. It's always off from what they're expecting." Whereas effeminate men have no other way of being understood than as gay in rural towns, the opposite is true for butch women. Like Nancy, in her comments presented at the beginning of this article, many women maintained that it is difficult to distinguish between rural heterosexual and lesbian women by using butch gender presentation. Rita said that, in the rural Midwest, "you can't tell whether women are or aren't because they all have potential!" Chelsea echoes this sentiment:

It's kinda funny around here, because you're, like, 'Hey, honey, is she "family"?' We'll be talking and it'll be, like, 'I don't know, she might just be a farmer hick.' You know, here's a woman with short hair, hiking boots, with a wallet in her back pocket ... no, she's just a farmer! 
Chelsea's example of a woman who is "just a farmer," but who also could be a lesbian because of her more butch gender practices, highlights how female masculinity is not categorically linked with lesbian sexuality in small towns.

Thus, the meanings of gender presentations are geographically specific. Although gender presentations, particularly more butch self-presentations, are a route to visibility for lesbians in urban areas, they do not always translate the same way in rural towns. For instance, when I asked Jenny if she thought she was visible as a lesbian in her small town, she replied, "We're pretty stereotypical. I mean, look at me, I'm in jeans, a T-shirt, and a hat ... but that's like the general attire of so many women here!" That non-feminine attire aligns with the "general attire" of heterosexual women in the area makes it less salient in achieving lesbian visibility. Xander agrees, noting that "if you're a flannel-wearing lesbian, they may not see the lesbian part of it," which he thinks makes life "easier" for rural lesbian women than for gay men.

I argue that these data reveal how individual butch gender presentations are not enough to make women's nonnormative sexuality visible in rural areas. Rather, being seen around town with a same-sex partner is a ruralspecific way of achieving visibility. This is particularly important for couples who describe themselves as more masculine, as most of the coupled rural women did. For instance, when I asked Jenny if other people knew she was in a same-sex couple, she said, "I just assume people know we are, because we go in together all the time." Evelyn's reflections echo Jenny's. Evelyn, who described "some parts of herself as butch," was living in a city, but wanted to move to the country. Interestingly, she imagines that being away from the city would lead to a decrease in the visibility of her sexual identity. Elaborating, she said, "In the city you're more visible to more people. In the country they aren't going to necessarily think anything of it unless they see you with somebody else." Particularly telling are her words "unless they see you with somebody else." Although Evelyn sees her sexual identity as visible in the city, she speculates that it would not be so in the country unless she was with a same-sex partner.

Understandings of female same-sex sexuality have historically been linked to displaying masculine gender presentations and having a samesex sexual partner (Chauncey 1982), and both continue to circulate. Although more butch-like individual gender presentations make lesbian identity visible in urban contexts (Kennedy and Davis 1993; Moore 2006), this is not the case in rural areas, where having a same-sex partner is more paramount in signaling lesbian sexuality. Interestingly, this is also 
the case for femme lesbian women across geographic contexts (Walker 2001). Although the sexual identity of rural butch lesbian women is not invisible in urban lesbian cultures, their more butch gender presentations do not do the same work in rural areas because those gender presentations are also tied to normative (hetero)sexuality.

\section{Conclusion}

Presuming that more lesbian than gay couples live outside urban areas in the United States, I analyze the mutually constitutive relationships among place, gender, and sexuality to assess why this might be the case. Constructions of female masculinity align with those of rurality and lesbian sexuality, which may leave room for some lesbians to be able to stay in rural places. Likewise, that constructions of male femininity align with gay sexuality but not rurality may mean that the ability for some gay men to stay put in rural areas might be constrained. How these categories are coconstructed sheds light on the gendered nature of acceptance for rural sexual minorities: Both lesbian women and gay men gain acceptance by engaging with masculinized practices and discourses. Finally, visibility of lesbian sexuality is achieved relationally (via a same-sex partner) rather than individually (via more butch gender presentations) given the degree to which all rural women, regardless of sexuality, enact more masculine presentations.

Rural lesbians' engagement with masculinity both reproduces and challenges the gender order in small towns. Rural lesbians challenge the rural gender order insofar as they assert sexuality not tied to men and disrupt the expectations that rural women be heterosexual. Yet their engagement with masculinizing practices and discourses reproduce the conflation of masculinity and rurality, which works to marginalize femininity as well as people who display nonnormative gender presentations. Thus, that more bodies may be privy to masculinity does not necessarily entail a revaluation of what practices constitute dominant and subordinate masculinities or femininities in rural areas.

These findings extend knowledge about rural sexual minorities by showing how gender matters for lesbian women in rural areas. Although both heterosexual and lesbian women might embrace female masculinities, this is not to say that sexuality is irrelevant. Rural sexual minorities face unique constraints not faced by rural heterosexuals or their urban counterparts, including, for instance, isolation and a lack of a visible, sustained gay community (Coby and Welch 1997; McCar- 
thy 2000). Future research could explore variations among rural regions in the United States, as the experience of sexual minorities in the rural Midwest might differ from those in the rural West or South. ${ }^{4}$ Another avenue of inquiry that warrants attention is how the coconstruction of space, gender, and sexuality shapes the experiences of people living in small towns who identify as transgender. Similarly, the question of how rural lesbian women construct nuanced butch identities remains unanswered.

This work also provides insights useful to understanding sexuality more broadly. First, it underscores the degree to which nonnormative sexuality is becoming delinked from nonnormative gender (Valentine 2007). Valentine (2007) argues that the emergence of the category "transgender" reflects how mainstream gay movements worked to distance gay and lesbian identity from gender variance. He suggests that the delinking might be more true for gay men than for lesbian women. Given the degree to which rural gay men, but not lesbian women, created a clear distinction between their sexual identity and gender nonnormativity, this article provides one empirical example that supports his assessment. Second, these findings also suggest that analyses of sexual minorities would benefit from a more explicit focus on femininity and masculinity. Work focused on gays and lesbians in other contexts should assess how the experiences of gay men or lesbian women might differ by gendered presentations.

In addition, this work extends understandings of masculinity. It indicates that the meanings of gender presentations differ across geographic contexts. Although female masculinity is the most visible gender presentation of lesbian identity in urban contexts, it does not hold the same meaning in rural contexts because masculine gender presentation is acceptable for all rural women, regardless of sexuality. Extending this finding more broadly, this work underscores that the meanings and values attributed to masculinity and femininity vary across context. The focus here is on geographic contexts. Yet future work can continue to incorporate this insight into work that asks how processes of defining and assigning value to masculinity and femininity occur in other contexts, including workplaces (Bernstein, Kostelac, and Gaarder 2003) and schools (Pascoe 2007), and what the implications of those processes are for men and women. Furthermore, in contrast to previous researching suggesting that women doing masculinity is culturally disruptive and personally transgressive, this work shows one instance of female masculinity that is normative. Importantly, the practices of masculinity in which rural lesbian women engage must be understood as specific to rurality. 
These findings draw attention to how an intersectional approach can enrich theorizing of masculinity. Overall, this work provides more empirical weight to the call in gender studies to disentangle masculinity from men and male bodies.

\section{Notes}

1. Five participants did not fill out the survey. I filled in the missing characteristics for these interviewees when this information was made available during the interview. Racial demographics for five interviewees is missing.

2. Moore shows that Black lesbians with masculine gender presentations can hold feminist beliefs and a desire to eradicate gender inequality (Moore 2006, 133). This is particularly important given the attacks on butch lesbian women (and, more recently, on FTM transmen) and butch-femme relationships as perpetuating patriarchy, embracing male privilege, and recreating unequal dynamics in lesbian relationships (for discussion of such attacks, see Halberstam 1998). Like Moore's, other work has illustrated how butches and transmen can be feminist and do not always gain social status (Dozier 2005; Nestle 1992; Schilt 2006).

3. Thanks especially to Nadine Hubbs for this point.

4. In terms of regional differences regarding gender and whether more traditional gender beliefs prevail in certain regions, research is mixed (Swank, Fahns, and Haywood 2011).

\section{References}

Almaguer, Thomas. 1993. Chicano men: A cartography of homosexual identity and behavior. In The lesbian and gay studies reader, edited by Henry Abelove, Michèle Aina Barale, and David M. Halperin. New York: Routledge.

Bell, D., and G. Valentine. 1995. Queer country: Rural lesbian and gay lives. Journal of Rural Studies 11:113-22.

Bell, S. E., and Y. A. Braun. 2010. Coal, identity, and the gendering of environmental justice activism in central Appalachia. Gender \& Society 24:794-813.

Bernstein, M., C. Kostelac, and E. Gaarder. 2003. Understanding "heterosexism": Applying theories of racial prejudice to homophobia using data from a Southwestern police department. Race, Gender \& Class 10:54-74.

Bettie, Julie. 2003. Women without class. Berkeley: University of California Press.

Bird, S. 2006. Masculinities in rural small business ownership: Between community and capitalism. In Country boys: Masculinity and rural life, edited by Hugh Campbell, Michael Bell, and Margaret Finney. University Park: Pennsylvania State University Press.

Boulden, Walter T. 2001. Gay men living in a rural environment. Journal of Gay and Lesbian Social Services 12:63-75. 
Brandth, Berit. 2006. Agricultural body-building: Incorporations of gender, body and work. Journal of Rural Studies 22:12-27.

Campbell, H., M. M. Bell, and M. Finney, eds. 2006. Country boys: Masculinity and rural life. University Park: Pennsylvania State University Press.

Chauncey, George Jr. 1982. From sexual inversion to homosexuality: Medicine and the changing conceptualization of female deviance. Salmagundi 58/59:144-46.

Coby, P., and P. Welch. 1997. Rural gay men in northern New England: Life experiences and coping styles. Journal of Homosexuality 33:51-67.

Connell, R. W. 1995. Masculinities. Berkeley: University of California Press.

Dozier, Raine. 2005. Beards, breasts, and bodies: Doing sex in a gendered world. Gender \& Society 19:297-316.

Emerson, R., R. Fretz, and L. Shaw. 1995. Writing ethnographic fieldnotes. Chicago: University of Chicago Press.

Falk, W., and L. M. Lobao. 2003. Who benefits from economic restructuring? Lessons from the past and challenges for the future. In Challenges for rural America in the twenty-first century, edited by D. L. Brown and L. E. Swanson. University Park: Pennsylvania State University Press.

Finley, N. J. 2010. Skating femininity: Gender maneuvering in women's roller derby. Journal of Contemporary Ethnography 39:359-87.

Gates, G. J., and J. Ost. 2004. The gay and lesbian atlas. Washington, DC: Urban Institute.

Gates, Gary J. 2010. Sexual minorities in the 2008 General Social Survey: Coming out and demographic characteristics. Los Angeles: The Williams Institute.

Gray, Mary L. 2009. Out in the country: Youth, media, and queer visibility in rural America. New York: New York University Press.

Halberstam, Judith. 1998. Female masculinity. Durham, NC: Duke University Press.

Hennen, Peter. 2008. Faeries, bears, and leathermen: Men in community queering the masculine. Chicago: University of Chicago Press.

Herring, Scott. 2007. Out of the closets, into the woods: RFD, country women, and the post-Stonewall emergence of queer anti-urbanism. American Quarterly 59:341-72.

Hill Collins, Patricia. 1990. Black feminist theory: Knowledge, consciousness, and the politics of empowerment. New York: Routledge.

Howard, John. 1999. Men like that: A Southern queer history. Chicago: University of Chicago Press.

Hubbs, Nadine. 2011. "Redneck woman" and the gendered poetics of class rebellion. Southern Cultures 17:44-70.

Hughes, Annie. 1997. Rurality and "cultures of womanhood." In Contested countryside cultures, edited by P. Cloke and J. Little. New York: Routledge.

Johnson, Patrick E. 2008. Sweet tea: Black gay men of the South. Chapel Hill: University of North Carolina Press.

Kazyak, Emily. 2011a. Disrupting cultural selves: Constructing gay and lesbian identities in rural locales. Qualitative Sociology 34:561-81. 
Kazyak, Emily. 2011b. "If we were rednecks": The classed and raced meanings of space. Unpublished manuscript.

Kennedy, E., and M. Davis. 1993. Boots of leather, slippers of gold: The history of a lesbian community. New York: Penguin Books.

Laore, C., and S. Fielding. 2006. Rooted and routed masculinities among the rural youth of North Cork and Upper Swaledale. In Country boys: Masculinity and rural life, edited by H. Campbell, M. Bell, and M. Finney. University Park: Pennsylvania State University Press.

Levitt, H. M., and K. R. Hiestand. 2004. A quest for authenticity: Contemporary butch gender. Sex Roles 50:605-21.

Little, J., and P. Austin. 1996. Women and the rural idyll. Journal of Rural Studies 12:101-11.

Little, Jo. 1997. Employment marginality and women's self-identity. In Contested countryside cultures, edited by Paul Cloke and Jo Little. New York: Routledge.

McCarthy, Linda. 2000. Poppies in a wheat field. Journal of Homosexuality 39:75-94.

Moore, Mignon. 2006. Lipstick or timberlands? Meanings of gender presentation in Black lesbian communities. Signs: Journal of Women in Culture and Society 32:113-29.

Morris, Edward W. 2008. "Rednecks," "ruters," and "'rithmetic": Social class, masculinity, and schooling in a rural context. Gender $\mathcal{E}$ Society 22:728-51.

Nagel, Joane. 2003. Race, ethnicity, and sexuality: Intimate intersections, forbidden frontiers. Oxford: Oxford University Press.

Nestle, Joan. 1992. The persistent desire: A femme-butch reader. New York: Alyson Books.

Pascoe, C. J. 2007. Dude you're a fag: Masculinity and sexuality in high school. Berkeley: University of California Press.

Rubin, G. 1992. Of calamites and kings: Reflections on butch, gender, and boundaries. In The persistent desire: A femme-butch reader, edited by Joan Nestle. Boston: Alyson.

Rupp, L. J., V. Taylor, and E. I. Shapiro. 2010. Drag queens and drag kings: The difference gender makes. Sexualities 13:275-94.

Sachs, Carolyn E. 1983. The invisible farmers. Totowa, NJ: Rowman and Allanheld.

Sachs, Carolyn E. 2006. Foreword. In Country boys: Masculinity and rural life, edited by H. Campbell, M. Bell, and M. Finney. University Park: Pennsylvania State University Press.

Schilt, Kristen. 2006. Just one of the guys? How transmen make gender visible at work. Gender \& Society 20:465-90.

Schippers, Mimi. 2002. Rockin' out of the box: Gender maneuvering in alternative hard rock. New Brunswick: Rutgers University Press.

Schippers, Mimi. 2007. Recovering the feminine other: Masculinity, femininity, and gender hegemony. Sociological Theory 36:85-102.

Shapiro, Eve. 2007. Drag kinging and the transformation of gender identities. Gender \& Society 21:250-71.

Smyth, Jolene D. 2007. Doing gender when home and work are blurred: Women and sex-atypical tasks in family farming. Ph.D. diss., Washington State University, Pullman, WA. 
Stein, Arlene. 2001. The stranger next door: The story of a small community's battle over sex, faith, and civil rights. Boston: Beacon Press.

Swank, E., B. Fahns, and H. Haywood. 2011. Traditional gender norms in Appalachia? Testing the distinctiveness hypothesis for gender role expectations, support of rape myths, and prevalence of sexual violence. Journal of Appalachian Studies 59:67-89.

Tickamyer, A. R., D. A. Henderson, J. A. White, and B. L. Tadlock. 2000. Voices of welfare reform: Bureaucratic rationality versus the perceptions of welfare participants. Affilia 15:173-92.

Tickamyer, A. R., and D. A. Henderson. 2003. Rural women: New roles for a new century. In Challenges for rural America in the twenty-first century, edited by D. L. Brown and L. E. Swanson. University Park: Pennsylvania State University Press.

United States Department of Agriculture. 2007. Rural definitions. http://www. ers.usda.gov/data/ruraldefinitions

U.S. Bureau of the Census. 2000. 2000 Summary File 1. Table GCT-P6: Race and Hispanic or Latino-State-Urban/rural and inside/outside metropolitan area. Washington, DC: U.S. Census Bureau.

Valentine, David. 2007. Imagining transgender. Durham, NC: Duke University Press.

Valochhi, S. 2005. Not yet queer enough: The lessons of queer theory for the sociology of gender and sexuality. Gender \& Society 19:750-70.

Walker, Lisa. 2001. Looking like what you are: Sexual style, race, and lesbian identity. New York: New York University Press.

Wilkins, Amy C. 2004. Puerto Rican wannabes: Sexual spectacle and the marking of race, class, and gender boundaries. Gender \& Society 18:103-21.

Wray, Matt. 2006. Not quite white. Durham, NC: Duke University Press.

\section{우우 ○ิ}

Emily Kazyak is assistant professor of sociology and women's and gender studies at the University of Nebraska-Lincoln. Her research interests are in sexuality, identity, and the law. Past work appears in Journal of Family Issues and Qualitative Sociology. Her current project examines legal decision making in LGBTQ families. 